\title{
ReFLEXões SOBRE AS RELAÇÕES DE TRABALHO DOCENTE NO ENSINO MÉDIO ESTADUAL PAULISTA
}

\author{
Reflections on the relationships of teacher's work in public secondary \\ school of São Paulo
}

\section{Reflexiones sobre las relaciones de trabajo docente en la educación pública secundária de São Paulo}

RESUMO O presente artigo tem como objetivo refletir sobre as relações de trabalho docente no setor público partindo da jornada de trabalho. É parte de uma dissertação de mestrado, cujo caminho metodológico foi a revisão da legislação e da bibliografia a respeito do trabalho docente, acompanhada de trabalho de campo - observação do cotidiano da escola e atividades realizadas pelos docentes e entrevistas com os mesmos - desenvolvido em uma única escola na Região Metropolitana de Campinas. Contrastando as prescrições estatais e as relações práticas construídas pelos docentes no cotidiano, foi possível perceber que: a) do ponto de vista do Estado, o trabalho docente é reduzido a uma concepção individual e celular, sem relação com local de trabalho; b) do ponto de vista docente, essa concepção os coloca "à deriva", uma vez que seu salário, conteúdo, horas e local de trabalho são flexíveis; c) professores e professoras constroem estratégias diversas para lidar com as determinações sobre o trabalho docente.

Palavras-Chave: JoRNADA DE TRABALHO. FLEXIBILIDADE. TRABALHO DOCENTE.

ABSTRACT This article aims to reflect on the relationship of teacher's work in public sector regarding the working day. It is part of a master's thesis whose methodological path was the revision of legislation and bibliography on teacher's work accompanied by fieldwork. The latter was developed in a single school in the Metropolitan Region of Campinas and consisted in observation of everyday activities in school and interviews with teachers. By comparing State prescriptions and practical relations built by teachers in daily life, it was possible to verify that: a) from State's point of view, the work of teachers is reduced to an individual and cellular conception, unrelated to their workplace; b) from a teacher's point of view, this conception puts them "adrift", since their salary, content of work, working hours and workplace are flexible; c) teachers conceive diverse strategies to relate to the determinants of their work.

KEY-WORDS: WORKING DAY. FLEXIBILITY. TEACHER'S WORK.

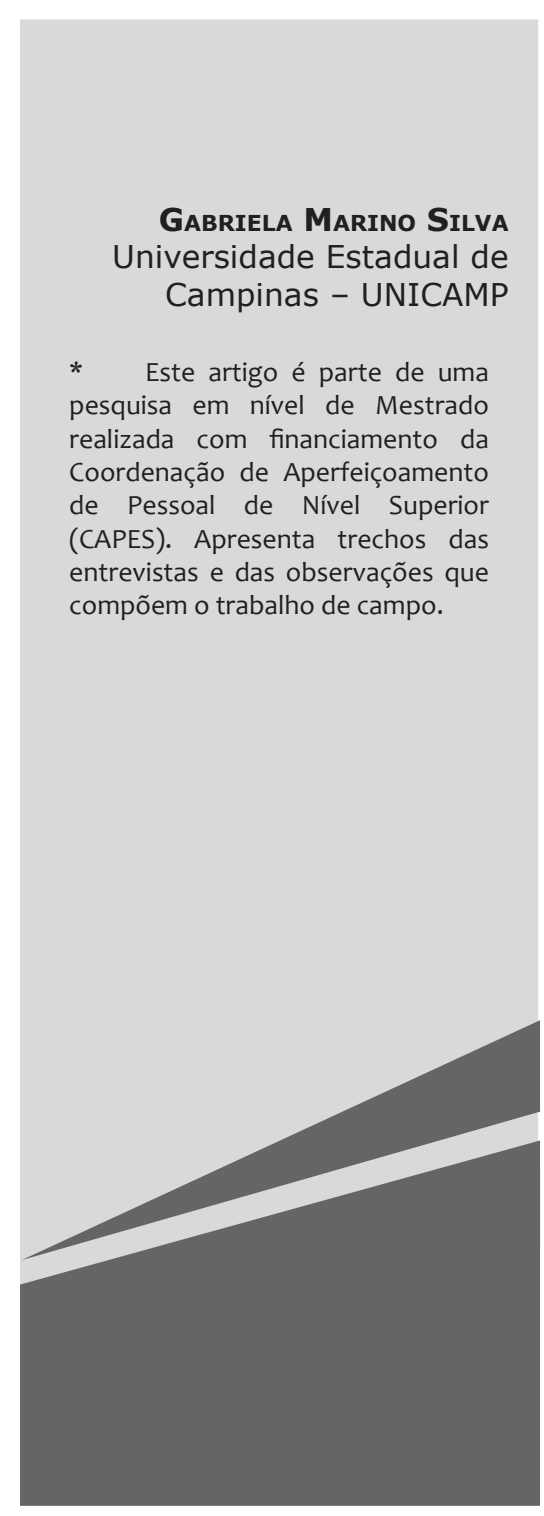


Résumen El presente artículo tiene como objetivo reflexionar sobre las relaciones de trabajo docente en el sector público, partiendo de la jornada laboral. Es parte de un trabajo de maestria, cuyo camino metodológico fue la revisión de la legislación y bibliografía sobre trabajo docente acompañada de trabajo de campo - observación del cotidiano de la escuela y actividades realizadas por los docentes y entrevistas con los mismos - desarrollado en una única escuela en la Región Metropolitana de Campinas. Contrastando las prescripciones estatales y las relaciones prácticas elaboradas por los docentes en el cotidiano, fue posible percibir que: a) desde el punto de vista del Estado el trabajo docente se reduce a una concepción individual y celular, sin relación con el lugar de trabajo; b) desde el punto de vista docente esta concepción los coloca "a la deriva", ya que su salario, contenido, horas y lugar de trabajo son flexibles; c) ellos elaborandiversas estrategias para tratar con las determinaciones sobre el trabajo docente.

PALABRAS ClaVe: JoRNAdA labORAL. FleXIBILIDAD. TRABAJO DOCENTE.

\section{INTRODUÇÃO}

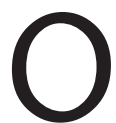
progresso técnico e/ou organizativo do trabalho altera não só a produtividade, mas também a intensidade do trabalho, como estudou Dal Rosso (1998). O autor observa que historicamente a redução da jornada é, em geral, acompanhada da intensificação do trabalho. Isso porque a jornada de trabalho é determinada socialmente, pela relação entre as classes antagônicas, e o Estado sintetiza essas disputas na forma da lei.

Por um lado, a jornada, em sua extensão e intensidade, determina as horas que o trabalhador fica à disposição para trabalhar, ou seja, como força de trabalho. Por outro lado, determina o tempo, bem como, a energia, que o trabalhador terá para a reprodução; para o lazer e o descanso; para ficar com a família, com os amigos etc. Enfim, para realizar as atividades para além do trabalho.

Para analisar a jornada de trabalho docente, no entanto, é necessário pensar as ambiguidades deste trabalho e suas especificidades como atividade de reprodução, especialmente quando desenvolvido na esfera pública, conforme o debate sintetizado em Hypólito et al. (1991).
De acordo com Silva (1992), o trabalho docente quando contratado pelo Estado é improdutivo - categoria cujo debate na literatura marxista é bastante extenso e não será retomado aqui -, isto é, não está diretamente ligado à produção de valor. No âmbito político, o autor observa uma tentativa de controlar o processo de trabalho docente a partir da burocratização e da vinculação a resultados. Todavia, não se altera sua natureza, que não permite controle total do processo.

Desse modo, ainda que não haja consenso na literatura em como compreender as relações de trabalho na esfera pública, o autor propõe olhar as condições sob as quais se realiza o trabalho docente, considerando o Estado como "empregador" e que o capital necessita dessa instituição para acumulação e legitimação. Tendo isso em vista, seguem algumas reflexões acerca das relações de trabalho docente na escola estadual paulista de nível médio a partir da jornada de trabalho.

\section{Metodologia}

A pesquisa de mestrado, da qual este artigo é resultado, baseou-se na realização de trabalho de campo, em diálogo com as reflexões de Caldeira (1991), Lang (1992), Oli- 
veira (1996) e Queiroz (1991). Foi desenvolvido durante o primeiro semestre letivo do ano de 2016, em uma única escola pública e estadual, localizada na Região Metropolitana de Campinas. Dessa forma, a coleta de dados deu-se pela observação do cotidiano da escola, com acompanhamento de aulas, reuniões e demais atividades desenvolvidas pelos docentes; e realização de entrevistas com professores e professoras que ministram aulas na escola, no ensino médio. Além disso, antes de iniciar o trabalho de campo, visando uma melhor compreensão das relações de trabaIho docente no estado de São Paulo (SP), foi feita uma extensa revisão dos documentos produzidos em nível federal e estadual (SP), com prioridade para o período dos governos democráticos mais recentes, junto à revisão da literatura sobre trabalho docente.

A seleção da escola teve como critérios 1) a indicação de que a escola seria objeto da reestruturação das escolas paulistas em 2016; 2) ser considerada, na opinião de professores, como referência de escola estadual que atende ao Ensino Fundamental II e o Ensino Médio; e, 3) a existência de coordenador pedagógico altamente qualificado, isto é, trata-se de um doutorando com pesquisas em educação. A escolha foi realizada com possibilidades de amplo acesso ao campo.

Com o intuito de contemplar um universo diverso de experiências docentes, os critérios de seleção de professoras/es a serem entrevistados foram: homens e mulheres que atuassem no ensino médio, sem distinção de períodos (manhã, tarde e noite); de diferentes disciplinas, buscando contemplar todas as áreas do conhecimento; com diversos contratos de trabalho (efetivos, temporários, estáveis, substitutos etc.), independente

\footnotetext{
Em 2015, o Governo de SP anunciou uma proposta de reorganizar as escolas estaduais em ciclos únicos, de forma que algumas unidades teriam apenas o Ensino Fundamental I, outras receberiam os estudantes do Ensino Fundamental II e outras seriam exclusivas do Ensino Médio. Entretanto, a proposta enfrentou forte resistência, com ocupação, pelos próprios estudantes, de mais de 80 escolas no estado. Tendo isso em vista, o Governo de SP adiou o projeto de reorganização
}

da escola a qual o cargo ou o contrato fosse vinculado; e de distintos momentos da carreira docente (iniciantes até os próximos da aposentadoria). Assim, na dissertação foram trabalhadas 17 entrevistas realizadas com 12 mulheres e 5 homens. Esse número, portanto, expressa aqueles que se dispuseram a participar, assinaram o Termo de Consentimento Livre e Esclarecido e não solicitaram a retirada da entrevista.

Os/as docentes entrevistados/as acompanham as características do conjunto de professores/as da escola. A maioria do quadro docente na escola é branca, ${ }^{2} \mathrm{com}$ experiência na docência e é composta por docentes em cargos de provimento efetivo, nos termos da Lei $n^{\circ}$. 10.261/1968- sendo que há alguns professores em contrato temporário, conforme a Lei Complementar nº 10.093/2009. São docentes altamente qualificados, de forma que todos/as entrevistados/as são formados/ as em licenciatura em nível superior e há seis deles formados em nível de pós-graduação (lato ou strito sensu).

\section{Pensando Praticamente a Jornada de TRABALHO}

A cada ano, no momento de atribuição de aulas, professores e professoras com cargos efetivos ou estáveis ${ }^{3}$ podem optar por uma jornada de trabalho, indicando no mo-

\footnotetext{
Há diversas formas de compreender a identidade racial dos sujeitos. Nesta pesquisa, que não tem o intuito de estudar as relações étnico-raciais, optou-se pela autodeclaração ou autoatribuição.

3 Por reivindicação dos docentes, estabeleceram-se dois processos que lhes conferiram estabilidade: o primeiro decorrente da Constituição Federal de 1988 (e seu desdobramento na constituição paulista de 1989) e outro pela lei estadual 1.010/2007. A Constituição Federal de 1988 garantiu estabilidade a todo servidor público civil que contasse com pelo menos cinco anos de exercício na data de sua publicação. Dessa forma, professores e professoras contratados como Admitido em Caráter Temporário (ACT) - conforme Lei $n^{\circ}$. 500/1974 - na época, e que cumpriam os requisitos, são considerados estáveis pela Constituição. A Lei Complementar $n^{\circ}$. 1.010/2007, em seu $\S 2^{\circ}$. do artigo $2^{\circ}$., conferiu estabilidade no emprego aos docentes temporários.
} 
mento deinscrição se desejam manter, ampliar ou reduzir sua jornada. Na Secretaria de Educação do Estado de São Paulo (SEE-SP), cada aula tem duração de 50 minutos e, dessa forma, as jornadas são assim organizadas na Resolução SE 08/2012:4

I) Jornada Integral de Trabalho Docente (40 horas):

a) Trinta e duas aulas em atividades com os alunos;

b) Três aulas de trabalho pedagógico coletivo na escola;

c) Treze aulas de trabalho pedagógico em local de livre escolha;

II) Jornada Básica de Trabalho Docente (30 horas):

a) Vinte e quatro aulas em atividades com os alunos;

b) Duas aulas de trabalho pedagógico coletivo na escola;

c) Dez aulas de trabalho pedagógico em local de livre escolha;

III) Jornada Inicial de Trabalho Docente (24 horas):

a) Dezenove aulas em atividades com os alunos;

b) Duas aulas de trabalho pedagógico coletivo na escola;

c) Sete aulas de trabalho pedagógico em local de livre escolha;

IV) Jornada Reduzida de Trabalho Docente ( 12 horas): ${ }^{5}$

4 A conquista da remuneração do trabalho docente realizado extraclasse - como correção de atividades e preparação de aulas - traduziu-se na Lei do Piso Salarial Profissional Nacional (Lei $\left.n^{\circ} .11 .738 / 2008\right)$, que prevê um valor mínimo de remuneração para os docentes em nível nacional e a garantia de um terço da jornada de trabalho para as atividades extraclasse. Na SEE-SP, a jornada de 40 horas (relógio) equivale a 48 horasaula (duração de 50 minutos), de forma que as 16 horas-aula que os professores têm correspondentes ao trabalho pedagógico configuram-se como $1 / 3 \mathrm{da}$ jornada em horas-aula.

5 Em extinção. A partir da atribuição de aulas de 2017, regulamentada pela Resolução SE 72/2016, os docentes não podem mais optar pela carga horária correspondente à Jornada Reduzida. a) Nove aulas em atividades com os alunos;

b) Duas aulas de trabalho pedagógico coletivo na escola;

c) Três aulas de trabalho pedagógico em local de livre escolha.

Para além da jornada de trabalho, os docentes efetivos podem somar uma carga suplementar de trabalho, de acordo com o Decreto $n^{\circ}$. 55.078/2009, inclusive em área diferente de atuação - desde que seja habilitado, isto é, tenha formação (licenciatura plena) para tal - com aulas livres e respeitando os limites máximos de:

I) Oito horas em atividades com alunos, quando em Jornada Básica de Trabalho Docente;

II) Treze horas em atividades com alunos, quando em Jornada Inicial de Trabalho Docente;

III) Vinte e três horas em atividades com alunos, quando em Jornada Reduzida de Trabalho Docente.

No entanto, a carga suplementar é composta por aulas atribuídas para além da jornada do docente, podendo ser atribuídas a outros docentes pela SEE-SP a qualquer momento. Além disso, o valor da hora/aula a título de carga suplementar é mais baixo.

Os professores admitidos no último concurso (2013) tiveram problemas com a composição da jornada, de forma que muitos deles optaram pela jornada disponível nas escolas e completaram a jornada com carga suplementar, como relata uma professora de Ciências Humanas:

Eu, aqui na casa não tem pra mim, só tem 10 aulas. Se eu tentar ampliar minha jornada, eu vou ter que ir pra outra escola. Então eu deixo nessa reduzida e aí eu posso pegar a suplementar, que aí eu completo as 32. Só que nessa situação. Por exemplo, eu completei com as aulas de geografia, aí são aulas livres, não tem professor nenhum. Mas se ele [o gover- 
nador] resolver chamar o pessoal do concurso e eles resolverem escolher aqui, eles podem pegar, porque minha carga é suplementar, não é minha. [Professora 04]

Entretanto, a forma como está organizada a carga suplementar, além de partir do pressuposto de uma flexibilidade quanto ao conteúdo do trabalho docente, entendido aqui como o campo disciplinar de formação superior, tem consequências e atinge diretamente a remuneração dos docentes, conforme relata outro professor admitido no último concurso:

Eu estava vindo o ano passado com uma carga horária de 32 horas/aulas no final de ano e chegou lá pro dia 15 de dezembro, que eu estava assumindo várias aulas como substituição, então porque lá na frente um diretor volta a assumir o cargo dele, então o vice-diretor volta pro lugar dele, daí o professor que estava assumindo volta pra dentro da sala de aula. Então você estava vindo com todas aquelas salas, daí chega no seu décimo terceiro, nas suas férias, tudo isso você perde. Ou seja, eu estava com 32 aulas, de repente você cai pra 10 aulas. Você só tem as suas aulas, de uma hora pra outra. E isso, isso que desmotiva, porque você vem - na hora que você vai entrar de férias, que vai receber pelas aulas que deu $o$ ano todo, de repente seu salário vai e cai pro mínimo: 700 reais, é o que eu recebi em janeiro, o que eu recebi em fevereiro. E quem paga suas contas com 700 reais hoje em dia? Ninguém. [Professor 05]

Essa forma de organização da jornada implica, portanto, no salário dos docentes ser flexível - de forma que, para a mesma aula, os docentes podem receber remuneração diferenciada - bem como, sua jornada de trabalho. Se, dadas as configurações da jornada, a professora opta por permanecer na escola com carga suplementar, essa opção implica uma incerteza: a qualquer momento, sua jornada de trabalho pode ser reduzida e essa decisão cabe ao Estado. Sua decisão sobre a amplitude da jornada, no caso de 12 horas, está vinculada ao local de trabalho, que também é flexível, pois se ela optar por ampliar a jornada, deve mudar de escola. A flexibilidade quanto ao local de trabalho aparece também em outras entrevistas.

Naquele ano, além dos docentes admitidos no último concurso, outros docentes também tiveram dificuldades com a composição da jornada. Uma professora compara o começo de sua carreira no início de 1990, quando era contratada como temporária, nos termos da Lei nº 500/1974, com o momento atual:

[...] não tinha professor, então eu ficava com aulas o ano inteiro, eram aulas livres mesmo! Não era licença, não era aula temporária, tinha que pegar pro ano inteiro. Tinha que garantir meu ano! (risadas). Então naquela época tinham essas aulas o ano inteiro, tinham menos professores acho que efetivos, então sobravam meio picadinho, mas sobravam: um pouco aqui, um pouco ali e hoje está voltando a ficar assim picadinho. Hoje está faltando aula, está diminuindo o número de aula, então o que acontece? A gente está começando a pegar picado de novo. [Professora 06]

A professora remete a uma época em que havia poucos efetivos, dessa forma, os professores temporários conseguiam atribuir aulas livres, ou seja, aquelas que não tinham sido atribuídas a qualquer professor, diferente das aulas temporárias, que são relativas a licenças (curtas ou longas) ou faltas. Mais adiante na entrevista, ela relata como teve suas aulas atribuídas na escola estudada, pois 
sua "sede" é outra escola. Como está em terceiro lugar na pontuação, precisou completar a jornada em outras escolas, de modo que essa estava dividida entre três locais de trabaIho durante o ano:

Então eu tive que picar de novo. E se você vai na atribuição, veja eu sou efetiva, eu estou quase me aposentando e tive que pegar em três escolas! E a minha sorte é que tinha esse bloco aqui com 24 aulas porque senão, se não tivesse essa escola eu ia estar dando aula em cinco escolas! Porque tinha um pouquinho numa escola, um pouquinho em outra escola, tudo picadinho assim! la ficar muito mais complicado. [Professora 06]

Dessa forma, podemos observar que, além de determinar o valor percebido por professores e professoras, a atribuição de aulas também determina, nitidamente, as condições de trabalho dos/as docentes. Outro professor também relata a organização da atribuição de aulas e as incertezas que o processo, da forma como acontece, traz:

Então eu sou um professor que estou dentro dessa escola, eu sou o quarto professor da lista, então é o último que atribui as aulas, então você tem que esperar passar o rodízio para todo mundo, então você não sabe se você vai ter aula, se você não vai ter aula, que escola que você vai dar aula. Então você nunca sabe o dia de amanhã. Então isso é angustiante pro professor. Então você se dedica muito na escola, dentro daqueles alunos, então chega no final do ano, você não sabe como que vai ser seu ano pro ano seguinte. E você passa Natal, Réveillon, todas as festas de final de

6 Os docentes têm o cargo associado a uma escola para fins de computação de frequência e tempo de serviço. ano e janeiro inteiro ansioso para saber o que que vai acontecer. Então isso trava também, por exemplo, eu gostaria de voltar a fazer o curso de Ciência da Computação, mas você tem uma inscrição num período totalmente diferente do ano. Então eu não posso simplesmente chegar na Unicamp "ah, vou estudar de terça e quinta”, vai levando o curso porque lá você tem essa possibilidade... daí de repente você tem aula aqui [na escola] terça-feira à noite, então daí você tem que trancar. Então você fica travado. Então a escola pública trava o professor, isso é angustiante. [Professor 05]

A organização flexível da jornada de trabalho deixa professores e professoras "à deriva". Mesmo aqueles que podem optar por uma jornada para a atribuição de aulas do ano seguinte não têm certeza que existirá o número mínimo de aulas na escola em que trabalham, tendo muitas vezes de mudar de local de trabalho ou trabalhar em várias escolas. Essa flexibilidade determina as condições de trabalho docente e incide diretamente sobre a remuneração. Desse modo, o planejamento da vida desses docentes fica "à deriva".

As relações entre flexibilidade e a sensação de estar à deriva já tinham sido discutidas por Sennett (2006). No primeiro capítulo de seu livro, o autor nos conta a experiência de um jovem casal que concretizara o "Sonho Americano" e cuja vida repleta de mudanças por conta do trabalho fazia surgir a preocupação de que "as medidas que precisava tomar e a maneira como tinha de viver para sobreviver na economia moderna houvessem posto sua vida emocional, interior, à deriva (SENNET, 2006, p. 19)". Isso porque o mercado global e as novas tecnologias, características distintivas do capitalismo atual, articulam "novas maneiras de organizar o tempo, sobretudo o tempo de trabalho (SENNET, 2006, p. 21)". E essa nova organização - imediatista e em constante mudança - leva à "experiência com 
a deriva no tempo, de lugar em lugar, de emprego em emprego" (SENNET, 2006, p. 27).

Pode ser observada na SEE-SP uma concepção de jornada de trabalho ancorada nas horas trabalhadas em sala de aula. O professor não é associado a um local de trabalho, no qual ocupa um posto de trabalho e cumpre a sua jornada. Ao contrário, seu trabalho é reduzido à relação de ensino e, portanto, à célula: a sala de aula. Seu trabalho é ensinar determinada disciplina, é individual, não se relaciona com as disciplinas dos colegas de trabalho. Essa concepção celular e individual que organiza o trabalho docente do ponto de vista do Estado implica flexibilidade. É funcional para abrir e fechar salas de aulas ou escolas e realocar os professores a qualquer momento. Ou seja, do ponto de vista do Estado, permite flexibilidade na gestão da Educação. Do ponto de vista docente, significa ficar "à deriva".

O trabalho docente também aparece nas entrevistas com professores/as como celular e individual. Quando perguntados quantas horas trabalham por dia, a maioria das respostas foi com relação às horas em sala de aula, sendo que, em sequência, faziam referência às Atividades de Trabalho Pedagógico Coletivo (ATPCs) e à jornada de trabalho oficialmente estabelecida.

Todavia, alguns ponderaram sobre o significado de horas trabalhadas, pois consideram o trabalho realizado fora da sala de aula e também o deslocamento entre as escolas, como podemos ver na fala reproduzida a seguir:

O que é trabalhar? Estar dentro de aula? Então, se é estar dentro de aula eu trabalho umas seis horas por dia. Mas se você for ver eu trabalho muito mais do que isso porque tem que corrigir coisas, tem que preparar aula, às vezes separar algumas coisas, material e isso leva tempo! Então se você for ver... a gente está trabalhando o tempo inteiro, no fundo! Porque às vezes eu estou em um lugar, num ambiente onde alguém fala alguma coisa e eu falo “isso dá pra aproveitar na minha aula! Espera aí, deixa eu anotar”. Aí você já pega o papel e já anota e já fala "nossa, ótima ideia, maravilhosa!" Então o tempo inteiro eu estou observando tudo ao meu redor e eu não sei o que se pode contar como tempo de trabalho, mas dentro de sala de aula são pelo menos seis horas por dia, no mínimo! Tem dia que é mais. [Professora 01]

Ainda que compreendam seu trabalho para além das horas em sala de aula, ele é sempre apresentado a partir da perspectiva individual e com relação à célula, ao ensino.

Amigues (2004) propõe olhar para o trabalho docente a partir da atividade, compreendida como a concepção e a organização do meio de trabalho para realizar as tarefas prescritas pela hierarquia, sendo que:

A tarefa refere-se ao que deve ser fei-
to e pode ser objetivamente descrita
em termos de condições e de objeti-
vo, de meios (materiais, técnicos...)
utilizados pelo sujeito. A atividade
corresponde ao que o sujeito faz
mentalmente para realizar essa tare-
fa, não sendo, portanto, diretamen-
te observável, mas inferida a partir
da ação concretamente realizada
pelo sujeito (AMIGUES, 2004, p. 39).

Compreende, assim, atividade como uma relação entre diversos objetos (prescrições, coletivos, regras do ofício e ferramentas) realizada por um sujeito histórica e socialmente constituído. Ela é orientada para os alunos, mas também para a escola, para os pais e para o executor da mesma, isto é, o próprio professor ou a própria professora. Nesse sentido, o resultado da atividade docente não seria a aprendizagem dos/as estudantes, mas a constituição dos meios de trabalho para que ensino e aprendizagem ${ }^{7}$ possam acontecer;

7 O autor chama a atenção que os processos de ensino e de aprendizagem são distintos e têm temporalidades próprias. O professor organiza os meios de trabalho coletivos para que os alunos tenham contato com o objeto de conhecimento, ferramentas etc. dentro do tempo de ensino que ele dispõe. A elaboração e reelaboração do conhecimento é um processo do aluno, que está para além do tempo do ensino. 
dessa forma as atividades residuais de preparação, avaliação, reelaboração etc., constituíram-se no cerne do trabalho docente, e não em "resíduos" do trabalho.

Esse olhar permite elucidar a relação entre tempo de ensino (trabalho em sala de aula) e tempo de trabalho docente, colocando professores e professoras no centro da perspectiva de análise, de modo a possibilitar perceber as contradições entre as múltiplas determinações do trabalho docente e a síntese que professores e professoras realizam cotidianamente em sua atividade. Na seção subsequente, focaremos nas contradições entre o trabalho prescrito, o trabalho real e aquilo que os docentes consideram como constituinte de seu trabalho.

\section{UM OLHAR SOBRE O TRABALHO DOCENTE NO COTIDIANO}

Para além das atividades que são reconhecidas como parte do trabalho docente, professores e professoras realizam uma série de tarefas que não consideram como constituintes de seu trabalho - e que muitas vezes negam como sendo parte desse - mas que o Estado lhes impõe. De que forma?

$\mathrm{Na}$ escola estudada, as reuniões de ATPCs aconteciam como encontro de formação entre docentes e coordenação. A coordenação organizava a reunião e propunha a temática a partir dos cursos de formação (obrigatórios) da SEE-SP. Nos encontros, foram discutidos diversos temas, como fatores extraclasse que influenciam a aprendizagem (especialmente as condições socioeconômicas); formas de avaliação; adaptação curricular para alunos de inclusão; uso de Tecnologias de Informação e Comunicação em aulas; diversidade etc.

Em uma reunião de ATPC, o coordenador estava discutindo com os professores para que eles entregassem no início de cada bimestre um planejamento de aulas, para que se pudesse verificar, ao final de cada bimestre, se o docente cumpriu com o planejado. Era o reforço de um pedido anterior que não estava sendo cumprido. Os docentes estavam claramente incomodados com a perspectiva, questionavam o que aconteceria se eles não cumprissem o planejamento proposto, se houvesse mudanças ao longo do bimestre etc.; pois, argumentavam, o trabalho é bastante imprevisível.

O coordenador pareceu desistir de receber os planejamentos de todos os docentes, mas, ao passar para o tópico seguinte da reunião, o clima não melhorou. Foi pedido que os coordenadores assistissem algumas aulas de cada professor ou professora e produzissem um relatório para a Diretoria de Ensino. Novamente, foi possível perceber resistência por parte dos/as docentes, ao mesmo tempo em que foram mais facilmente convencidos a permitir a entrada dos coordenadores. Há, portanto, políticas que procuram controlar o trabalho docente e que impõem tarefas aos mesmos.

Foi proposto, durante outra reunião de ATPC, que os professores desenvolvessem um planejamento de aulas multidisciplinares juntando-se a colegas de disciplinas distintas. O primeiro impasse foi que os docentes não teriam tempo ou espaço para um planejamento conjunto, de forma que ficou decidido que fariam isso durante as próprias reuniões de ATPC. Alguns pareceram empolgados com o planejamento de aulas multidisciplinares e logo começaram a trabalhar, enquanto ficou clara a resistência de outros.

A proposta tinha por objetivo melhorar o desempenho dos estudantes da escola nas habilidades e nos conteúdos da Avaliação de Aprendizagem em Processo, ${ }^{8}$ de modo que alguns professores não viam ligação entre sua disciplina e a participação no projeto. Assim, durante a apresentação da plataforma digital

8 É uma prova diagnóstica aplicada duas vezes ao longo do ano letivo, em fevereiro e agosto, para alunos a partir do $2^{\circ}$. Ano do Ensino Fundamental, Anos Finais do Ensino Fundamental e todos os anos do Ensino Médio. O caderno de perguntas é formado por uma redação e questões dissertativas e de múltipla escolha de Língua Portuguesa e Matemática, tendo como base o conteúdo do Currículo Oficial do Estado de São Paulo. 
na qual estava registrado o desempenho dos/ as estudantes nas últimas edições da avaliação, o coordenador foi questionado, passando parte da apresentação argumentando que as habilidades exigidas (como interpretação de texto, resolução de problemas etc.) poderiam ser trabalhadas em várias disciplinas para além de Língua Portuguesa e Matemática. Não obstante, uma das professoras de Matemática questionou a relação entre as habilidades averiguadas pela avaliação e o próprio conteúdo da disciplina.

Essa política delineia uma perspectiva de controlar o trabalho docente: verificar se os professores estão cumprindo o conteúdo do material didático (estilo cartilha) fornecido pela SEE-SP, visando melhorar o desempenho dos alunos em exames de avaliação externa, ${ }^{9}$ melhorando os índices educacionais da escola - o que pode trazer recursos para a escola e para os professores na forma de bônus.

Essa perspectiva reforça a noção de cumprimento de metas, cobrança de resultados, mensuração do aprendizado e de mérito, por meio de políticas de punição/recompensa. Laval (2009) observa que a influência dos valores da esfera privada foi grande nas décadas finais do século passado e, em consonância com eles, as políticas educacionais foram desenvolvidas a partir de critérios desta esfera: desempenho em avaliação externa, possibilidades de comparação, competitividade, cumprimento de metas, mensuração e quantificação do conhecimento e definição de importância de certas áreas do conhecimento em detrimento de outras.

Um último exemplo, por sua vez, causou um embate direto com os gestores (coordenadores e diretora) da escola: a instituição da Secretaria Escolar Digital, uma plataforma

9 Ao longo das décadas de 1990 e 2000, foram desenvolvidos novos índices para medir a qualidade da educação. Para além das convencionais taxas de evasão e defasagem idade-série, as avaliações externas de desempenho de estudantes, especialmente em Matemática e Língua Portuguesa, instituíram-se como protagonistas da avaliação da qualidade educacional e, por conseguinte, consolidaram-se como os principais norteadores das políticas públicas em educação. on-line na qual os professores deveriam inserir notas e frequência dos/as estudantes ao final de cada bimestre. A discussão entre os docentes era de que eles não deveriam realizar a inserção digital das notas, pois já registravam tudo nos diários de classe, sendo que caberia a um/a funcionário/a da escola fazê-lo. A direção argumentava que a falta de funcionários impedia que o trabalho fosse realizado pelos mesmos e que, portanto, caberia aos próprios docentes fazê-lo. As/os professoras/ es questionavam em que momento deveriam fazê-lo, pois também tinham muito trabalho. A postura final foi de que não aceitariam levar mais trabalho para casa, sendo que deveriam então usar os horários de ATPC para a inserção das notas na plataforma, acordo que foi acatado pelos gestores.

Dessa forma, o ATPC configurava-se como um espaço formação, mas também de trabalho, no qual os/as docentes inseriam as notas no novo sistema, corrigiam atividades e atribuíam notas no final do bimestre, entre outras tarefas extraclasse.

Dal Rosso (2008) analisa o processo histórico de intensificação do trabalho, considerando que o grau de intensidade, constituinte do trabalho concreto, é definido pelo conflito entre capital e trabalho. O autor diferencia a produtividade, que seria o aumento de resultados do trabalho no mesmo tempo, da intensidade, referente ao aumento ou redução de dispêndio de energia no trabalho. Ou seja, a intensidade diz respeito ao trabalho concreto, que mobiliza força física, emocional, psíquica e intelectual no processo de trabalho.

Ao analisar o trabalho no início do século XXI, o autor define alguns principais instrumentos de intensificação: 1) alongamento da jornada, 2) ritmo e velocidade, 3) acúmulo de atividades, 4) polivalência, versatilidade e flexibilidade e 5) gestão por resultados. Esses não são observáveis em todos os setores da economia com a mesma relevância, pois a intensificação do trabalho é um processo altamente heterogêneo.

De acordo com o autor, o alongamento da jornada é explicado principalmente a partir 
das horas extras no setor privado. Entretanto, entre os professores da escola pública em São Paulo, o alongamento da jornada se dá mediante possibilidade legal de acúmulo de cargos, além do trabalho extraclasse realizado pelo professor.

Segundo a pesquisa do autor, a educação foi o setor que apresentou maior resistência às medidas de intensificação de ritmo e velocidade, especialmente por sua dinâmica própria no que tange ao tempo do ensino. Entretanto, todas as atividades para além da sala de aula são perfeitamente passíveis de intensificação de ritmo e velocidade. Além disso, podemos observar também um grau de intensidade altíssimo de trabalho imposto no que tange ao número de alunos. Se compreendermos o trabalho docente como a atividade realizada por eles, transitando entre as prescrições e sua relativa autonomia para lidar com as mesmas, é possível perceber o movimento de sua intensificação também, conforme descrito nas tarefas exigidas de professores e professoras citadas, como a digitação de notas. Isso porque as novas tarefas impostas só podem ser realizadas pelos docentes por meio do alongamento da jornada, levando o trabalho para casa, e do aumento do ritmo e velocidade da realização das tarefas na mesma jornada.

Além disso, conforme Dal Rosso (2008), a não contratação de novos funcionários leva ao acúmulo de atividades e tarefas daqueles que estão empregados. Na escola, a falta de trabalhadores técnico-burocráticos conduz a práticas de acúmulo de tarefas por parte dos trabalhadores que estão ativos e, por conseguinte, também, à polivalência..$^{10}$ Os docentes realizam, então, tarefas que não são suas, de acordo da divisão do trabalho tradicionalmente praticada na escola. Dessa forma, o governo economiza recursos com contratação e as tarefas continuam sendo cumpridas por intermédio da intensificação do trabalho.

10 Polivalência é, para o autor, a capacidade de realizar diversos trabalhos dentro do mesmo tempo, ou seja, mais trabalho dentro da mesma jornada.
Por fim, o autor compreende que a cobrança por resultados impõe uma pressão interna e/ou externa para o trabalhador por mais trabalho, sendo, portanto, uma forma de intensificação. Em geral, o cumprimento de metas é atrelado a formas flexíveis de remuneração, como o bônus. Coloca-se assim a perspectiva de punição/premiação como princípios da gestão.

Segundo Hypólito (2011), as novas formas de gerenciamento trouxeram várias mudanças para a Educação pública, modificando-a em diferentes aspectos: a formação, o processo de trabalho, a organização escolar, a gestão, o currículo. Ao submeter as escolas à lógica de mercado, precarizou-se e se intensificou o trabalho docente. Entretanto, ao se observarem os índices educacionais, a melhoria é pouco significativa e dificilmente justifica todas as onerações que o Estado assumiu. A única lógica explicativa é a redefinição do controle, o qual, segundo o autor:

[...] não é mais realizado com supervisoras cotidianamente fiscalizando o trabalho docente, mas é efetivado na escola com uma vigilância externa, via controle curricular e gerencial. Os exames padronizados, os sistemas de avaliação e os índices de desempenho regulam o que deve ser ensinado e como deve ser ensinado. Os livros didáticos, os $\mathrm{PCN}$, as grades de competências e outros materiais são o guia distante, mas efetivo, para orientar todas as práticas de ensino no cotidiano escolar.

No entanto, isso não seria suficiente se não houvesse alguma estratégia para melhor avaliar o professorado. Para isso, além das reformulações curriculares nos cursos de formação, mais voltadas para a construção de currículos práticos, tem havido tentativas - até agora fracassadas - de criar pro- 
vas para avaliação e certificação da docência. Por outro caminho, isso pode ser obtido via avaliação docente nos próprios sistemas, com estágios probatórios e modelos de carreira mais flexíveis, sem estabilidade, com contratação temporária (HYPÓLITO, 2011, p. 15).

Os docentes procuram resistir, individualmente, e enquanto um pequeno coletivo na escola opõe-se a realizar as tarefas burocráticas, negociam o horário de trabalho, não entregam os planejamentos, fazem de conta que estão realizando os trabalhos multidisciplinares, as feiras culturais-científicas, entre outros projetos que, muitas vezes, não têm sentido para eles.

Ao mesmo tempo em que a jornada de trabalho é organizada a partir de uma concepção celular e individual do trabalho docente, tomando como base a sala de aula e o ensino, o trabalho realizado pelos/as docentes durante essa jornada ultrapassa, e muito, essa perspectiva.

No cotidiano, professores e professoras realizam seu trabalho docente enquanto atividade relativamente autônoma; no entanto, em sua relação com o Estado, nas horas em que está "disponível” para o trabalho, o professor deve realizar aquilo que lhe é demandado. Desse modo, a autonomia docente esbarra em seus limites estruturais: as determinações do trabalho vêm - ou parecem vir - por intermédio do Estado (norma), ainda que a sua determinação real esteja na relação capital-trabalho.

Diferentemente de considerar a esfera dos direitos como momento livre de determinações do modo de produção - ou até como uma oposição ao capital, como é tomado em alguns casos -, a apresentação das relações entre trabalho e educação exige enfrentar suas próprias contradições. Ou seja, a forma de relação social estabelecida entre o Estado e o direito não como o "outro do capital”, mas como forma derivada de suas relações de propriedade, e que, ao mesmo tempo, implica em resistências para a realização plena do capital (CATINI, 2016, p. 279).

Assim, partindo de uma compreensão dinâmica das relações sociais e do professor como trabalhador, foi possível perceber que as imposições do Estado, que resultam de disputas e determinações "para além dos muros da escola", encontram ainda resistência, não só de forma organizada, tradicionalmente através de entidades sindicais, mas também no cotidiano.

\section{CONSIDERAÇões FINAIS}

A organização da jornada de trabalho pelo Estado constrói-se a partir de uma concepção de trabalho docente celular e individual. É reduzida à relação com a sala de aula e ao ensino, sem relação com o local de trabalho. Essa forma de organização deixa os docentes "à deriva", uma vez que seu salário é flexível, o número de horas de trabalho é flexível, a jornada é flexível, o local de trabalho é flexível, o período de trabalho é flexível, e o conteúdo do trabalho é flexível.

Professores e professoras relacionam-se com a jornada de trabalho do ponto de vista individual. No entanto, no tocante às contradições entre o trabalho real e o prescrito, a resistência aparece, mesmo que muitas vezes com caráter conservador, partindo da divisão do trabalho na escola e das práticas estabelecidas. 


\section{REFERÊNCIAS}

AMIGUES, R. Trabalho do professor e trabalho do ensino. In: MACHADO, Ana R. O ensino como trabalho: uma abordagem discursiva. Londrina: EDUEL, 2004.

BRASIL. Constituição (1988). Constituição da República Federativa do Brasil. Brasília, DF: Senado: Centro Gráfico, 1988.

BRASIL. Lei $\mathrm{n}^{\circ}$. 11.738, de 16 de julho de 2008. Regulamenta a alínea "e" do inciso III do caput do artigo 60 do Ato das Disposições Constitucionais Transitórias, para instituir o piso salarial profissional nacional para os profissionais do magistério público da educação básica. Brasília, DF, 2008. Disponível em: http://www.planalto.gov.br/ccivil_03/_ato2007-2010/2008/lei//11738. htm Acesso em: 23/05/2018.

CALDEIRA, T. P. do R. Memória e relato: A escuta do outro. Revista Arquivo Municipal - Memória e ação cultural, v. 200, 1991.

CATINI, C. R. Força de trabalho, sujeito do direito e educação: notas introdutórias. Perspectiva, Florianópolis, v. 34, n. 1, p. 262-285, jan./abr. 2016.

DAL ROSSO, S.O debate sobre a redução da jornada de trabalho. São Paulo: Associação Brasileira de Estudos do Trabalho - ABET, 1998. (Coleção ABET - Mercado de Trabalho, v. 5.)

HYPÓLITO, A. M.et al. Dossiê: interpretando o trabalho docente. Teoria \& Educação, n.4, 1991. HYPOLITO, A. M. Reorganização Gerencialista da Escola e Trabalho Docente. Educação: Teoria e Prática - v. 21, n. 38, Período out./dez.2011.

LANG, A. B. da S. G. Documentos e depoimentos na pesquisa histórico-sociológica. In: LANG, A. B. da S. G. (Org.). Reflexões sobre a pesquisa sociológica. São Paulo: CERU, 1992, série 2.

LAVAL, C. A escola não é uma empresa. Londrina: Planta, 2009.

OLIVEIRA, R. C. de. O Trabalho do Antropólogo: Olhar, Ouvir, Escrever. In: Revista de Antropologia,v. 39, n. 1 (1996), p. 13-37.

QUEIROZ, M. I. P. de. Variações sobre a técnica de gravador no registro da informação viva. São Paulo, T. A. QUEIROZ LTDA., 1991.

SÃO PAULO (Estado). Constituição (1989). Constituição do Estado. São Paulo. São Paulo, 1989. Disponível em: http://www.al.sp.gov.br/repositorio/legislacao/constituicao/1989/constituicao-0-05.10.1989.html. Acesso em: 29/11/2016.

SÃO PAULO (Estado). Decreto $\mathbf{n}^{\circ}$. 55.078, de 25 de novembro de 2009. Dispõe sobre as jornadas de trabalho do pessoal docente do Quadro do Magistério e dá providências correlatas. Disponível em: http://www.al.sp.gov.br/norma/?id=158462 Acesso em: 23/05/2018.

SÃO PAULO (Estado). Lei nº 10.261, de 28 de outubro de 1968. Dispõe sobre o Estatuto dos Funcionários Públicos Civis do Estado. Disponível em: https://www.al.sp.gov.br/norma/?id=28593. Acesso em: 20/09/2017.

SÃO PAULO (Estado). Lei nº.500, de 13 de novembro de 1974. Institui o regime jurídico dos servidores admitidos em caráter temporário e dá providências correlatas. São Paulo, 1974. Disponível em: http://www.al.sp.gov.br/StaticFile/documentacao/lei_500.htm Acesso em: 23/05/2018.

SÃO PAULO (Estado). Lei Complementar $\mathbf{n}^{\circ} \mathbf{. 1 . 0 1 0}$, de $\mathbf{1}^{\circ}$. de junho de 2007. Dispõe sobre a criação da SÃO PAULO PREVIDÊNCIA - SPPREV, entidade gestora do Regime Próprio de Previdência dos Servidores Públicos - RPSP e do Regime Próprio de Previdência dos Militares do Estado 
de São Paulo - RPPM, e dá providências correlatas. São Paulo, 2007. Disponível em:http://www. al.sp.gov.br/repositorio/legislacao/lei.complementar/2007/lei.complementar-1010-01.06.2007. html Acesso em: 29/11/2016.

SÃO PAULO (Estado). Lei Complementar nº. 1.093, de 16 de julho de 2009. Dispõe sobre a contratação por tempo determinado de que trata o inciso X do artigo 115 da Constituição Estadual e dá outras providências correlatas. São Paulo, 2009. Disponível em: http://www.al.sp.gov.br/ norma/?id=156956. Acesso em: 23/05/2018.

SÃO PAULO (Estado). Resolução SE nº 08, de 19 de janeiro de 2012. Dispõe sobre a carga horária dos docentes da rede estadual de ensino. Disponível em: http://www.educacao.sp.gov.br/ lise/sislegis/detresol.asp?strAto $=201201190008$. Acesso em: 23/05/2018.

SÃO PAULO (Estado). Resolução $n^{\circ}$. 75, de 28 de novembro de 2013. Dispõe sobre o processo anual de atribuição de classes e aulas ao pessoal docente do Quadro do Magistério. Disponível em: http://www.educacao.sp.gov.br/lise/sislegis/detresol.asp?strAto=201311280075 Acesso em: 29/11/2016.

SÃO PAULO (Estado). Resolução SE nº 36, de 25 de março de 2016. Institui, no âmbito dos sistemas informatizados da Secretaria da Educação, a plataforma "Secretaria Escolar Digital", onde deverão constar os dados de avaliação e frequência dos alunos, atualizados bimestralmente, disponíveis para o acompanhamento dos quadros gestores e dos pais ou responsáveis. Disponível em:http://www.educacao.sp.gov.br/lise/sislegis/detresol.asp?strAto=201605250036. Acesso em: 20/09/2017.

SÃO PAULO (Estado). Resolução SE nº 72, de 22 de dezembro de 2016. Dispõe sobre o processo anual de atribuição de classes e aulas ao pessoal docente do Quadro do Magistério. Disponível em:http://siau.edunet.sp.gov.br/ItemLise/arquivos/72_16.HTM?Time=17/06/2018\%20 12:43:06Acesso em: 22/06/2018.

SÃO PAULO (Estado). SEE-SP. Avaliação de Aprendizagem em Processo. Diagnostica o nível de aprendizado dos estudantes matriculados na rede estadual de ensino. Disponível em: http:// www.educacao.sp.gov.br/avaliacao-aprendizagem. Acesso em 20/09/2017.

SENNETT, R. A corrosão do caráter: consequências pessoais do trabalho no novo capitalismo. Rio de Janeiro: Record, 2006.

SILVA, T. T. da. O que produz e o que reproduz em educação. Ensaios de sociologia da educação. Porto Alegre: Artes Médicas, 1992. Cap. 9.

\section{SOBRE A AUTORA}

Gabriela Marino Silva

Mestra em Educação pela Faculdade de Educação da Universidade Estadual de Campinas. Possui bacharelado e licenciatura em Ciências Sociais (Sociologia) pela mesma instituição. Integrou a Linha de Pesquisa "Trabalho e Educação" e o "Grupo de Estudos e Pesquisa em Diferenciação Sociocultural” (GEPEDISC).

E-mail: gaabimarino@gmail.com

Recebido em: 29/05/2018

Aprovado em: 02/07/2018 